\title{
SKEPTICAL HYPOTHESES AND MORAL SKEPTICISM
}

\author{
A REPLY TO MAY
}

Jimmy Alfonso Licon

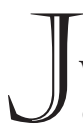

OSHUA MAY argues that epistemic closure arguments for skepticism are weaker in the moral domain than in the perceptual domain. ${ }^{1}$ Epistemic closure is a prominent approach to defending perceptual skepticism. ${ }^{2}$ May gives the following example:

1. I'm not justified in believing that: I'm not a BIV [brain in a vat].

2. I am justified in believing that: I have hands entails I'm not a BIV.

3. If I'm justified in believing that $p$ and that $p$ entails $q$, then I'm justified in believing that $q$.

4. So: I'm not justified in believing that I have hands. ${ }^{3}$

Moral skeptics might be tempted to run an epistemic closure argument of their own. But May argues that such arguments are "ultimately weaker when applied to morality compared to perception." Call this the implausibility thesis. May defends the implausibility thesis in a couple of ways.

First, May argues that we cannot formulate an argument for moral skepticism using epistemic closure arguments: such arguments require that our evidence fails to support our ordinary beliefs (e.g., moral, perceptual) better than a competing skeptical hypothesis. May thinks it is hard to see how our actual moral evidence would be the same if moral nihilism (or a comparable skeptical hypothesis) were true. Second, May argues that the phenomenon of "imaginative resistance" to morally devious claims (e.g., we can imagine a fictional world where we are in the Matrix, but not where torturing babies would be morally justified) intuitively motivates the claim that basic moral truths hold necessarily.

1 May, "Skeptical Hypotheses and Moral Skepticism."

2 Cf. Dretske, "Epistemic Operators"; Brueckner, "The Structure of the Skeptical Argument."

3 May, "Skeptical Hypotheses and Moral Skepticism," 244.

4 May, "Skeptical Hypotheses and Moral Skepticism," 341. 
And if basic moral truths are metaphysically necessary, then it is not "possible for there to be a scenario in which the beliefs are illusory."

In this paper, I argue that May's defense of the implausibility thesis is unconvincing. Even if closure arguments for perceptual and moral skepticism fail, May has not offered good reason to think that an epistemic closure argument for moral skepticism would be less plausible than perceptual skepticism-it could be, after all, that each kind of skepticism is equally plausible, and equally wrong. Specifically, there are two places where May's case for the implausibility thesis is unconvincing.

First, I find May's claim that the closure argument for moral skepticism cannot plausibly meet the equal evidence claim (i.e., the evidence for one's ordinary belief that $p$ does not provide better evidence for $p$ than a skeptical hypothesis) unconvincing. I defend this claim by sketching a closure argument for moral skepticism comprised of an evolutionary debunking account of our actual moral evidence, along with the possibility of moral nihilism, which satisfies the equal evidence claim.

Second, May's claim that imaginative resistance to morally deviant claims in fiction is an intuitive way to motivate the necessity of basic moral claims is wrongheaded. A serious issue with the move from imaginative resistance to the necessity of basic moral truths is that we can easily evoke imaginative resistance in cases where there are no relevant truths that hold necessarily (e.g., describing a pile of rotting garbage as lovely evokes imaginative resistance; but the claim that rotting garbage is not lovely is not a good candidate for a necessary truth). Even if basic moral truths do hold necessarily, imaginative resistance is poor evidence of this.

May plausibly argues that epistemic closure arguments for moral skepticism require an additional component beyond moral nihilism as a live hypothesis. Closure arguments require that (i) moral nihilism is a live epistemic possibility, and (ii) moral evidence is no better support for our moral beliefs than moral nihilism, to show by epistemic closure that we lack moral knowledge. May offers the following example:

1. I am not justified in believing that moral nihilism is false.

2. I am justified in believing that $(p)$ "It is morally wrong to torture babies for fun” entails (q) "Moral nihilism is false." 
3. If I am justified in believing that $p$, and I am justified in believing that $p$ entails $q$, then I am justified in believing that $q$.

4. Therefore, I am not justified in believing that $(p)$ it is morally wrong to torture babies just for fun. ${ }^{6}$

May thinks that some philosophers wrongly think that moral nihilism as a live hypothesis is enough to formulate an epistemic closure argument for moral skepticism. ${ }^{7}$ The fact that moral nihilism is an epistemic possibility is the start of an epistemic closure argument for moral skepticism; but as May plausibly argues, it is insufficient by itself:

While the brain-in-a-vat and evil demon scenarios are genuine skeptical scenarios, moral nihilism alone isn't. Moral nihilism is just the metaphysical view that there are no moral facts. The analog of moral nihilism in the debate about perceptual skepticism is something like idealism... We need further details showing that one cannot rule it out, and in a way that renders one's beliefs unjustified. ${ }^{8}$

It is not enough that there are metaethical possibilities that we cannot rule out. If we have good evidence in favor of moral optimism - roughly the non-skeptical view that moral reality is more or less the way it seems - it would not matter that we cannot rule out the possibility that moral nihilism is true. Skeptical arguments construed as epistemic closure, whether they are moral or perceptual, require evidential underdetermination: we should be skeptical in cases where our overall evidence simply underdetermines whether the moral optimist or moral nihilist hypothesis is true.

As Vogel puts the point (applied to perceptual skepticism):

One way of understanding such skepticism ... is to construe it as an underdetermination problem.... [If] you have just as much reason to think that something else is the cause of your experience, your belief that there is a tree in front of you is arrived at arbitrarily and doesn't amount to knowledge. Skeptical arguments, as I understand them, are meant to establish that every one of our perceptual beliefs faces competition from an equally good alternative. It would follow that we are never in a position to know anything about the world. ${ }^{9}$

6 May, "Skeptical Hypotheses and Moral Skepticism," 343-44.

7 E.g., Sinnott-Armstrong, Moral Skepticisms, 79.

8 May, "Skeptical Hypotheses and Moral Skepticism," 345.

9 Vogel, "Skeptical Arguments," 427, second and third emphases added. 
May concludes that if a closure argument for moral skepticism works, then it must satisfy the equal evidence requirement (he calls this the "equal evidence claim") that "the evidence for one's ordinary belief that $p$ (e.g., I have hands) does not provide better evidence for $p$ than for skeptical hypothesis $q$ (e.g., I'm a handless BIV)." ${ }^{\prime 0}$ There is a similar constraint on closure arguments for perceptual skepticism: the perceptual skeptic argues not just that we cannot rule out the BIv hypothesis, but also that our evidence for such a hypothesis is roughly as good as our evidence for our perceptual beliefs.

But why does May think the equal evidence claim cannot be met in the moral case? For one thing, we might think that evolutionary debunking explanations could help here. May worries that an appeal to such explanations fails to "describe a scenario illustrating that the reasons for our moral beliefs fail to provide better support for their truth rather than the hypothetical scenario that they are illusory."11 Debunking explanations are just too weak to be formulated as closure arguments as they offer undermining defeaters for our moral beliefs. May thinks that such explanations would not satisfy the equal evidence claim as skeptical arguments from epistemic closure "must illustrate something about our actual evidence-namely, that it underdetermines the skeptical versus non-skeptical hypotheses. Without this further explanation, we're left with only the claim that our evidence could be faulty in the relevant way." ${ }^{2}$

If combining an evolutionary debunking explanation and a live moral nihilist hypothesis operates like a closure argument for perceptual skepticism, the debunking explanation must (i) be formulated as a serious possibility that our evidence does not rule out, but also (ii) satisfy the equal evidence claim such that our actual moral evidence underdetermines whether a moral nihilist or moral optimist hypothesis is true. We must motivate the claim that our actual evidence would be the same on either the moral nihilist or moral optimist hypothesis. ${ }^{13}$

But the moral skeptic has an answer. First, consider a strain of perceptual skepticism: we cannot rule out that we are being deceived by an evil demon, and we would have the perceptual evidence on either the evil demon hypothesis or ordinary world hypothesis. And as we cannot rule out the evil demon hypothesis, our perceptual evidence does not justify our perceptual beliefs. The moral skeptic can make a similar move here by formulating a closure-style argument for their view: in a universe where moral nihilism is true but evolutionary processes operate on social creatures like us, we would have the moral evidence that

May, "Skeptical Hypotheses and Moral Skepticism," 346.

May, "Skeptical Hypotheses and Moral Skepticism," 350.

May, "Skeptical Hypotheses and Moral Skepticism," 350.

May expresses doubt about this; "Skeptical Hypotheses and Moral Skepticism," 347. 
we actually have. We would have the same intuitions, seemings, and so forth regardless of whether moral nihilism or moral optimism is true in that such evidence is adaptive (e.g., it influences our beliefs, and actions — and natural selection cares about that).

Why think that our actual moral evidence would equally underdetermine the moral optimist or moral nihilist hypothesis? ${ }^{14}$ Based on the basic account defended by evolutionary debunkers, certain actions would seem required of us categorically, even on the moral nihilist hypothesis. Here is a plausible suggestion: on the moral nihilist hypothesis, we have evolutionary reasons to expect that having a moral capacity that issues moral judgments is adaptive. And this capacity must have a firm psychological grip to motivate us to think and act in moral terms. It is not sufficient merely to believe that we should follow moral directives. Rather, it must seem that acting morally is nonnegotiable such that if one believes an action is "required by an authority from which he cannot escape [namely, morality] ... then he is more likely to perform that action." ${ }^{15}$

Although specifying what counts as moral evidence is hard, I take it that the moral skeptic would be prima facie justified using such a conception of moral evidence, as it is modeled after practices used by moral philosophers (e.g., using counterexamples to criticize act utilitarianism). This is plausible in that (i) things like seemings, intuitions, deliberations, and so forth are the kind of evidence used by moral philosophers - and it is unclear what else would count as moral evidence such that it could not be captured in evolutionary terms. But (ii) if May holds that closure arguments for moral skepticism cannot satisfy the equal evidence claim, and rejects this conception of moral evidence, he owes us a distinct but plausible conception of moral evidence that blocks epistemic closure arguments for moral skepticism. Without good reason to think otherwise, the moral skeptic is within her rights to model her conception of moral evidence on that used by moral philosophers. Surely, if intuitions, deliberations, counterexamples, seemings, and the like exhaust our moral evidence, then the moral skeptic can plausibly argue that an epistemic closure argument can satisfy the equal evidence claim: evolutionary processes would have produced the

14 There is an ambiguity here between two claims: (a) Our moral evidence (E) equally supports the moral skeptical hypothesis $\left(\mathrm{H}_{1}\right)$ and the non-skeptical hypothesis $\left(\mathrm{H}_{2}\right)$; and, (b) our moral evidence would be the same whether $\mathrm{H}_{1}$ or $\mathrm{H}_{2}$ were true. If we take (a) and (b) as roughly equivalent, this suggests a probabilistic interpretation of the evidence, in say Bayesian or likelihoodist terms. This is not to claim allegiance to a probabilistic take on the evidence, but to point out that if we do take (a) and (b) to be equivalent, framing the moral evidence in probabilistic terms would help cash out that equivalence. Thanks to an anonymous referee for pressing this point. 
same moral evidence, whether the moral nihilist or moral optimist hypothesis is true. $^{16}$

May might object here that at best evolutionary explanations only partially explain our actual moral evidence. We should not expect to have our same overall moral evidence for evolutionary reasons, whether the moral nihilist or moral optimist hypothesis is true: some moral evidence like intuitions and seemings are adaptive; but other evidence is not. For example, the intuition that every person should be treated equally ceteris paribus is not obviously adaptive; but it still plausibly comprises part of our actual moral evidence. Contrast this with perceptual skepticism: the skeptic has a story to tell (e.g., the deceptive practices by an evil demon) about why we would have the same perceptual evidence, whether our perceptual beliefs or the evil demon hypothesis is true.

But this objection is not convincing: the evolutionary debunker need not suppose that all of our moral evidence is adaptive to provide an evolutionary explanation of our actual moral evidence. We should expect to have the same evidence, whether the moral optimist or moral nihilist hypothesis were true for evolutionary reasons: on the moral nihilist hypothesis, informed by an evolutionary account of evidence, our moral evidence is partially a by-product of evolutionary processes favoring those with certain cognitive abilities (e.g., the intuition that all persons are equal would be an evolutionary by-product of our moral capacities operating in a specific cultural context). On this scenario, our moral evidence would support our moral beliefs and the moral nihilist hypothesis equally.

Evolutionary debunking arguments for moral skepticism can operate similarly to closure arguments for perceptual skepticism: we have a reason to hold that (i) moral nihilism could be true and (ii) our moral evidence would be the same whether the moral optimist or moral nihilist hypothesis is correct-on the evolutionary account, our actual moral evidence is adaptive (or an evolutionary by-product); and (ii) prima facie satisfies the equal evidence claim.

May also argues that the metaphysical necessity of moral truths supports the implausibility thesis: if moral truths hold necessarily_-where there are no possible worlds in which we would have the same moral evidence, but with different or

16 May mentions that some moral beliefs might be basic such that they are warranted independent of moral evidence, i.e., we have a default "entitlement" to them ("Skeptical Hypotheses and Moral Skepticism," 357n7). While this might be, it is irrelevant when it comes to evaluating the implausibility thesis: this might be true of some of our perceptual beliefs. 
absent moral facts - then there cannot be a "scenario in which the beliefs are illusory-in which they seem true but aren't." ${ }^{17}$ Without possible worlds of that sort, moral skeptics cannot run a closure-style argument for their view. ${ }^{18}$

May thinks that imaginative resistance is an intuitive way to motivate the metaphysical necessity of basic moral truths: while we can fictionally entertain far-fetched and implausible scenarios, it is hard to imagine fictional scenarios where deviant moral claims are true (e.g., a story where women are morally inferior to men would evoke such resistance). ${ }^{19}$ This imaginative resistance can be explained if basic moral truths hold necessarily (e.g., like imagining a world where $2+2$ does not equal 4 as $2+2$ necessarily equals 4 ). If moral truths hold necessarily, we could not imagine possible worlds where the moral truths are different or absent (call this the necessity explanation). May thinks that the necessity explanation blocks closure arguments for moral skepticism: such arguments require metaphysical possibilities where we have the same moral evidence, but the moral facts vary.

But the necessity explanation is implausible: we can evoke imaginative resistance about contrived concepts. ${ }^{20}$ Suppose that an object is gumbish if it is squishy, and emits a screeching noise. The claim that a palm tree in a thriller is gumbish would evoke imaginative resistance: palm trees are not squishy and do not emit screeching noises. ${ }^{21}$ The fictional claim that palm trees are gumbish would evoke imaginative resistance even if there is nothing gumbish in the world: the gumbish concept does not apply to palm trees; but that does not tell us whether gumbish claims hold necessarily. ${ }^{22}$

Here is another example: an author who just announces that rotting garbage is beautiful would evoke imaginative resistance in their readers. This imaginative resistance is not evidence that aesthetic truths are necessarily true. Similar to the gumbish example, the takeaway is that imaginative resistance in the moral

17 May, “Skeptical Hypotheses and Moral Skepticism," 353.

18 May also mentions that moral truths might be known a priori ("Skeptical Hypotheses and Moral Skepticism," 343). I will not discuss this possibility, but it is an area where May is on firmer footing; see Shafer-Landau, "Evolutionary Debunking, Moral Realism, and Moral Knowledge," 35.

19 Gendler, "The Puzzle of Imaginative Resistance," 55.

20 For a more developed version of this line of thought, see Levy, "Imaginative Resistance and the Moral/Conventional Distinction."

21 Something that resembles (but is not) a palm tree might be gumbish—but that is beside the point.

22 If there is nothing gumbish in the actual world, then there are no gumbish truths that hold necessarily. For one thing, there would be nothing to ground gumbish truths across all possible worlds. 
case tells something about how to apply moral concepts (i.e., if the relevant supervenience base is present, then the concept applies) not whether basic moral truths hold necessarily. Thus, we should be skeptical that imaginative resistance to morally deviant fictional claims is evidence that basic moral truths (if there are any) hold necessarily. Basic moral truths might hold necessarily, but imaginative resistance is not good evidence of this.

To conclude, May's defense of the implausibility thesis falters in a couple of ways. He argues that even if "coupled with a genealogical debunking explanation, moral nihilism does not amount to a skeptical scenario in the relevant sense, since it ... [fails to establish] the Equal Evidence Claim." ${ }^{23}$ But, as I have argued, the moral skeptic can formulate her skeptical challenge to satisfy the equal evidence claim with a moral nihilist hypothesis that relies on an evolutionary account of our moral evidence.

I also argued that imaginative resistance is poor evidence that moral truths hold necessarily: we can evoke imaginative resistance in cases where there are no necessary truths that could explain such resistance (e.g., describing a bloody murder scene as "refreshing" evokes imaginative resistance; but it is not clear that a bloody murder scene necessarily is not refreshing). But if imaginative resistance fails to give us evidence for the necessity of aesthetic claims in the bloody murder scene example, then we should worry that it fails in the moral case too.

Finally, problems with the implausibility thesis aside, May's paper helps clarify the nature of closure arguments for moral skepticism. Nonetheless, motivating moral skepticism using epistemic closure remains a fruitful but underdeveloped approach that merits further discussion.

Towson University jimmylicono1@gmail.com

\section{REFERENCES}

Brueckner, Anthony. “The Structure of the Skeptical Argument.” Philosophy and Phenomenological Research 54, no. 4 (December 1994): 827-35. 
Dretske, Fred. "Epistemic Operators." Journal of Philosophy 67, no. 24 (December 24, 1970): 1007-23.

Gendler, Tamar Szabó. “The Puzzle of Imaginative Resistance." Journal of Philosophy 97, no. 2 (February 2000): 55-81.

Joyce, Richard. The Evolution of Morality. Cambridge, MA: MIT Press, 2006.

Levy, Neil. "Imaginative Resistance and the Moral/Conventional Distinction." Philosophical Psychology 18, no. 2 (April 2005): 231-41.

May, Joshua. "Skeptical Hypotheses and Moral Skepticism." Canadian Journal of Philosophy 43, no. 3 (2013): 341-59.

Shafer-Landau, Russ. "Evolutionary Debunking, Moral Realism, and Moral Knowledge." Journal of Ethics and Social Philosophy 7, no. 1 (December 2012): $1-37$.

Sinnott-Armstrong, Walter. Moral Skepticisms. Oxford: Oxford University Press, 2006.

Vogel, Jonathan. "Skeptical Arguments." Philosophical Issues 14, no. 1 (October 2004): 426-55. 